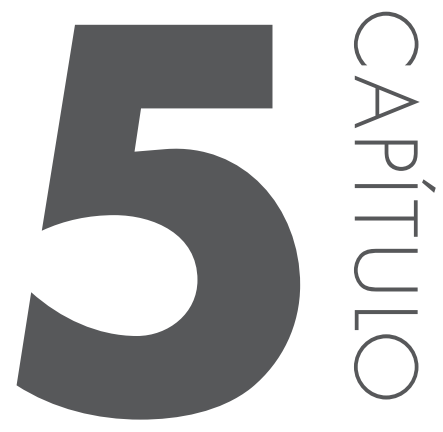

Eloisa Carvalho de Araujo

\title{
PROCESSOS RECENTES DE URBANIZAC̣ÃO EM TERRITÓRIO FLUMINENSE: ○ FENÔMENO da dispersão sob a ÓtICa DA INFLUÊNCIA DE GRANDES PROJETOS URBANOS14
}

O presente artigo decorre de um recorte temporal e espacial sobre pesquisa em curso cuja apresentação busca construir uma visão crítica, a partir de recentes processos pelos quais passam cidades como São João da Barra, Campos e Macaé, na região norte, Rio das Ostras, Cabo Frio e Araruama, na região das Baixadas Litorâneas e Niterói, Maricá e Itaboraí na região Metropolitana, do fenômeno da dispersão em território fluminense. O crescimento urbano pelo qual passam os municípios citados, sobretudo se considerarmos a influência dos grandes projetos urbanos contribuem por replicar, em muitas situações as práticas e formas urbanas encontradas na metrópole fluminense.

\footnotetext{
14 Este estudo foi desenvolvido no âmbito do projeto: "Infraestrutura e Cidade: relações entre espaço e meio ambiente", financiado inicialmente pela FAPERJ, integrado ao Grupo de Pesquisa do CNPq "Cidade, Processos de Urbanização e Ambiente", com estudos, sobre o território fluminense, através de três linhas de pesquisa, Processos de Urbanização e Ambiente, Dispersão Urbana e Instrumentos de Intervenção Urbana, no âmbito do Laboratório do Lugar e da Paisagem (LUPA/EAU/UFF).
} 
A pesquisa orienta-se por reconhecer nas múltiplas paisagens urbanas, aspectos no campo dos instrumentos jurídico-urbanísticos que acentuem a transformação de uso do solo e a valorização da questão ambiental.

O tema abordado no presente artigo, visa prospectar a partir de reflexões sobre a temática do processo de exploração do petróleo e gás e da instalação dos Complexos Industriais Logístico-Portuário e Naval, como estes incidem sobre a transformação e a transfiguração da paisagem econômica e social das cidades fluminenses.

A investigação territorial é orientada a partir do estudo que valoriza a vertente regional. O qual, só pode ser contemplado integralmente quando se trabalha numa perspectiva interdisciplinar.

A experiência em se trabalhar através da escala regional, onde parte das Bacias Petrolíferas, de Campos e de Santos ${ }^{15}$, se inserem, representa bem a questão primordial que a perspectiva sócio-urbana-ambiental possibilita. Muito das especificidades que se observam nos municípios alvo, podem ser explicitadas através dos diferentes ecossistemas, ultrapassando fronteiras ${ }^{16}$ geográficas e administrativas. $\mathrm{O}$ que nos permite abrir uma perspectiva interessante, pois exige-nos demonstrar as conseqüências da atuação humana sobre o território, a nível local e regional.

Ao mesmo tempo que as atividades econômicas, apesar de serem diversas, tendem a guardar uma certa homogeneidade quanto ao nível de desenvolvimento, introduzindo, em diferentes escalas, tensões e conflitos, entre a cidade que pulsa e a urbanização que é delineada, dia a dia, surgem novas formas resultantes de um processo de mudança contínua.

Expressando necessariamente a problemática vivenciada no interior deste espaço de conteúdo sócio-urbano-ambiental e geográfico, os problemas que se colocam na escala local deparam-se com um leque variável de problemas. Problemas em termos de degradação dos recursos naturais, da construção de uma ordem urbana mediada por instrumentos jurídico-urbanísticos, com base na função social

15 As Bacias petrolíferas de Campos e de Santos conformam estados da federação como Espírito Santo, Rio de Janeiro e São Paulo, Paraná e Santa Catarina. A Bacia de Campos, responsável por responsável por $85 \%$ da produção nacional de petróleo, se estende do estado do Espírito Santo (próximo a Vitória) até Arraial do Cabo, no litoral norte do Estado do Rio de Janeiro. Já a Bacia de Santos, no litoral fluminense, compreende municípios que vão de Cabo Frio a Paraty. No presente estudo privilegiamos os municípios do Estado do Rio de Janeiro, que correspondem às regiões de planejamento denominadas, norte, metropolitana e das baixadas litorâneas.

16 Fronteira aqui definida como um espaço concebido, de aspecto aparente, apresentando espaços de contorno, os quais estão referidos a um centro, de que é preciso traçar a configuração. O traçado da configuração do centro põe como limite a configuração do entorno. 
da cidade, da produção e transformação de ambientes urbanos. E que apesar destes se inter-relacionarem com municípios vizinhos e serem por eles impactados, podem ser percebidos diferentemente pela população em sua expressão mais íntima.

A comparação dos municípios selecionados, permitirá entender melhor a dinâmica das relações no interior de cada cidade e o reflexo na região, as inter-relações sociais, culturais e ambientais, mostrando também os altos níveis de complexidade e interdependência regional .

Outro aspecto relevante na área de estudo está vinculado a incorporação de áreas no processo de expansão de um núcleo através de vias principais de penetração. Ora pode ser o sistema ferroviário, como fator mais antigo, ou o sistema rodoviário, como fator mais moderno, mas também o mar como elemento de conexão entre as atividades econômicas.

Por um lado, está na integração de áreas, mesmo que mais distantes, que apresentam condições favoráveis ao uso da terra, seja para fins residenciais, turísticos ou industriais, a peculiaridade deste estudo.

Está na análise dos mecanismos de ação e estratégias utilizadas por seus agentes a explicação de uma paisagem mutável e suas variações no espaço e no tempo, seja pela formação histórica, seja pela formação econômica da estrutura social. Paisagem esta que reflete também novos estilos de vida de grupos sociais que se instalam no local, produzindo uma paisagem que continua a se modificar e a se diversificar visivelmente ante os novos fatos.

A relação espaço-tempo era tratada pela geografia como "espaço do tempo presente no espaço"17 e como "o espaço como uma desigual acumulação de tempos"18. As tendências atuais, no campo dos projetos urbanos ${ }^{19}$, demonstram prioridade absoluta ao espaço. Mas por outro lado, valoriza-se também as relações tempo/espaço nos processos de mudança social. Espaço-tempo, ligados à produção, ou mesmo, tornando-se mercadoria, é intencionalmente manipulado e considerado como objeto político, por agentes sociais.

Considerando esta abordagem, Lefebvre (1995) ressalta que para compreender a realidade e as novas concepções do espaço, outras dimensões sociais devem ser consideradas como as representações e o espaço, destacando nas mesmas a experiência do vivenciado, do percebido e do imaginado. Ainda para o autor, para

17 GEORGE, Pierre. O meio ambiente. São Paulo: Difel, 1973.

18 SANTOS, Milton. Por uma geografia nova. São Paulo: HUCITEC/Edusp, 1978.

19 PANERAI, Phillipe. O retorno à Cidade: o espaço público como desafio. São Paulo: Revista Projeto no. 173. São Paulo, pp.78-82.1994. 
além destas questões há de se valorizar tanto a construção individual e coletiva dos seus moradores diante da reprodução do espaço. E, nesse sentido, o direito à cidade, passa a ser visto por Lefebvre (1991) como um direito inalienável à vida, onde o espaço social deixa de ser apenas uma condição e um produto, mas passa a ser meio para o processo conflituoso, exacerbado pelo capitalismo.

Segundo Harvey (2005) para entender as novas formas urbanas é fundamental estabelecer uma relação entre cultura pós-moderna e os novos modelos de reprodução do capital, os modelos de acumulação flexível. O autor, ressalta que concepções de tempo e espaço devem ser consideradas em função das práticas e processos materiais de reprodução da vida social. Enquanto o espaço sofre atuação humana significativa a partir de interesses divergentes e de grupos diversos, o tempo comanda a vida social, seja através dos eixos de deslocamento, seja através do uso de formas associadas aos serviços e equipamentos urbanos. Nessa perspectiva, o autor busca realçar as fases da vida dos indivíduos considerando o registro do tempo gasto nas práticas sociais, em especial na vida cotidiana, sem deixar de enfatizar a dualidade na qual se baseiam as práticas no desenvolvimento capitalista. O autor também sugere, através do processo de desterritorialização/reterritorialização dos espaços evocado por Guattari e Deleuze, que configuração territorial também se apoia na nossa percepção cultural do tempo espaço. O que, nos permite sugerir, para compreender nos momento de crise, a percepção do espaço, que um evento pode ao mesmo tempo ter conseqüências em múltiplos espaços, de forma sincronizada ou não.

Para Giddens (1991), tal processo é agravado pelo fato de que a modernidade é inerentemente globalizante e acena para a existência de um mundo exterior, mais extensivo e perigoso, que conduz, cada vez mais, a uma transformação da intimidade no enfrentamento dos desafios.

$\mathrm{Na}$ área investigada, a expansão urbana recente vem assumindo, novos contornos derivados de grandes projetos urbanos associando novos desafios ao planejamento urbano e regional.

Apartirdessespressupostosopresenteartigopretendesedesenvolverconsiderando quatro seções. A primeira, ao introduzir o tema, apresenta inquietações fruto da temática escolhida com repercussão nas áreas objeto da pesquisa, onde a investigação territorial é orientada a partir do estudo que valoriza tanto a abordagem espaço-tempo, como a relação local-regional. A segunda seção ressalta, na delimitação do objeto de estudo, considerações a respeito da revisão do conceito de dispersão urbana; $\mathrm{Na}$ terceira, o espaço urbano metropolitano é apresentado em um contexto da dispersão urbana, propiciando reflexões quanto aos enfrentamentos da cidade contemporânea. Por fim, a última seção, sugere a identificação, seleção e priorização de ações, na perspectiva de readequar iniciativas governamentais às especificidades da região 


\subsection{A DELIMITAÇÃO DO OBJETO DE ESTUDO CONSIDERANDO A REVISÃO DO CONCEITO DE DISPERSÃO URBANA}

A abordagem espacial da região de estudo vem por considerar, no presente artigo, dois aspectos em especial, a visão espacial que impõem uma relação de interdependência, e por outro, a preocupação com o esgotamento dos recursos. As reflexões sobre a temática do processo de exploração do petróleo e gás e da instalação dos Complexos Industriais Logístico-Portuário e Naval, assim como, a inserção do Complexo Petroquímico do Rio de Janeiro - Comperj, além de atividades correlatas, e como estes incidem sobre a transformação e a transfiguração da paisagem econômica e social da região norte do Estado do Rio de Janeiro vem por merecer da presente autora investigações no campo dos processos de urbanização e ambiente. Nesse sentido nos utilizamos de alguns conceitos articuladores como "urban sprawl" ou dispersão urbana, territórios de fronteira e empréstimo de território ${ }^{20}$, para instigar uma discussão e reflexões sobre o fenômeno da dispersão sob a ótica da influência de grandes projetos urbanos.

Através de uma releitura da noção de dispersão urbana, como procedimento inicial de uma análise urbana sobre as regiões e cidades sob influência de grandes projetos urbanos, nos propomos a reflexões que contribuam enquanto desafios ao planejamento territorial em um contexto de cidades sustentáveis, valorizando o diálogo interdisciplinar.

A expansão, por exemplo, das atividades ligadas à extração de petróleo e gás natural na Bacia de Campos, na costa sudeste brasileira, ao longo desses últimos anos, têm contribuído significativamente para a retomada do crescimento da economia local e regional, concentrando grande parte de suas atividades nos municípios de Macaé, Rio das Ostras e Campos dos Goytacazes. Já o Complexo Portuário e Logístico do Açu, no município de São João da Barra, além de servir às indústrias que deverão se instalar no seu distrito industrial deverá estar apto a receber cargas destinadas a outros portos nacionais e até do Atlântico Sul. Por outro, a instalação do Complexo Petroquímico do Rio de Janeiro, no município de Itaboraí, integrante da porção leste da metrópole fluminense, exigiu a preparação de um quadro legal, no âmbito ambiental-urbano que pudesse dar suporte ao empreendimento.

Frente a esta nova realidade e as modificações urbanísticas, econômicas e sociais previstas para a região, com base nas dinâmicas espaciais em curso, podemos considerar que se vive uma verdadeira dispersão nos novos territórios.

\footnotetext{
20 PANERAI, Phillipe. O retorno à Cidade: o espaço público como desafio. São Paulo: Revista Projeto no. 173. São Paulo, pp.78-82.1994.
} 
Ao considerar que o processo de urbanização dispersa é mais evidente em lugares onde os índices de urbanização vem demonstrando índices mais elevados, pode-se notar que nessas localidades existe a formação de áreas que se assemelham à práticas metropolitanas, em geral de porte médio, que possuem uma ou mais centralidades que determinam, ao seu redor, áreas urbanizadas dispersas (REIS, 2007). Nesse aspecto vale mencionar o crescimento urbano pelo qual passam os municípios citados, sobretudo se considerarmos a influência dos grandes projetos urbanos com variações nas atividades da indústria petrolífera, petroquímica, e, correlatas, replicando, em muitas situações as práticas e formas urbanas encontradas na metrópole fluminense. Tal influência iniciou-se a partir do período entre $1996 \mathrm{e}$ 2010, o que pode ser verificado com o incremento da população.

\begin{tabular}{|c|c|c|c|c|}
\hline Municipio & 1996 & 2000 & 2010 & 2014 (Estimativa) \\
\hline São João da Barra (*) & 28.129 & 27.682 & 32.747 & 34.273 \\
\hline Campos dos Goytacazes (*) & 389.547 & 406.989 & 463.731 & 480.648 \\
\hline Macaé (*) & 112.971 & 132.461 & 206.728 & 229.624 \\
\hline Rio das Ostras (**) & 28.106 & 36.419 & 105.676 & 127.171 \\
\hline Cabo Frio $(* *)$ & 101.401 & 126.828 & 186.227 & 204.486 \\
\hline Araruama $(* *)$ & 66.148 & 82.803 & 112.008 & 120.948 \\
\hline Maricá $(* * *)$ & 60.286 & 76.737 & 127.461 & 143.111 \\
\hline Niterói $(* * *)$ & 450.364 & 459.451 & 487.562 & 495.470 \\
\hline Itaborai $(* * *)$ & 184.560 & 187.479 & 218.008 & 227.168 \\
\hline
\end{tabular}

$\left({ }^{*}\right)$ Municipios integrantes da Região Norte Fluminense

${ }^{(* *)}$ Municipios Integrantes da Região das Baixadas Litorâneas

Tabela 5.1 - Municípios selecionados influenciados pelas atividades petrolíferas, petroquímicas e correlatas2.4. Fonte: IBGE, Censos Demográficos e Estimativas

A partir desse contexto tanto a região Norte do Estado do Rio de Janeiro, como as regiões das Baixadas Litorâneas e Metropolitana (na sua porção leste), vem demonstrando passar por grandes transformações econômicas, sociais e espaciais em torno da atuação do setor industrial com repercussão nos setores residencial e de serviços. Esta abordagem pode ser percebida através da atuação dos agentes públicos e privados sobre o espaço urbano.

As cidades escolhidas, têm contribuído para evidenciar o surgimento de novas formas espaciais, como também, a partir da apropriação das mesmas, das tensões entre o ambiente urbano e tecnológico em produção.

Até bem recentemente, se observava na região um crescente dinamismo urbano, apoiado, sobretudo, nas expectativas de movimentação de um mercado de terras e imobiliário, na criação de novos postos de trabalho, a partir do surgimento das 
instalações industriais e na implantação de um processo de descentralização espacial. Tal impacto tinha em seu caráter de previsibilidade, repercussões no que se refere ao adensamento das suas áreas urbanas, nas alterações da estrutura de uso e ocupação do solo e na ampliação das demandas por serviços básicos e infraestrutura urbana e social (ARAUJO,2006).

(...) A região conhecida, como Baixada Litorânea localizada no estado Rio de Janeiro, teve nos últimos anos um crescente processo de urbanização. A atividade turística e o veraneio têm um importante papel para o desenvolvimento dos municípios da região, ao atrair a atenção para os atrativos físicos da região, como as belas praias, e a exuberante vegetação de Mata Atlântica, ainda preservada em algumas áreas, como por exemplo, na Área de Proteção Ambiental do Pau Brasil, em Cabo Frio. Entretanto, o crescimento urbano, sem planejamento eficiente cria espaços de contradições, contribuindo para a valorização de algumas localidades em detrimento de outras. (R.M.F.M. PINTO et al., 2011:192)

Salienta-se, na região, a percepção da fragilização de áreas de considerável acervo ambiental frente ao crescimento urbano, ressaltando as contradições do processo de urbanização e o ambiente, contribuindo para sérios problemas socioambientais. Discute-se na região, o Projeto de União das Baixadas Litorâneas, que tem como objetivo redistribuir igualitariamente, entre os municípios envolvidos, os royalties do petróleo para a criação de um fundo de urbanização, favorecendo os municípios que dispõem de um repasse menor.

Segundo Pinto et al.(2011), o que pode ser verificado na região das Baixadas Litorâneas é a sobrevalorização do solo urbano, sobretudo, próximo à costa, ficando os moradores mais carentes com as partes menos visadas pelo capital. Dessa forma, a população menos abastada se apropria de terrenos em locais considerados inadequados para moradia, construindo casas em locais como encostas íngremes e áreas alagadiças, sujeitas a sofrerem desabamentos de terra devido ao processo de erosão agravado pelas chuvas e pelo desmatamento.

A autora considera que o desenvolvimento das cidades é decorrente da construção de casas de veraneio, resorts, hotéis e pequenos apartamentos, todos estes destinados a classes mais elevadas que podem pagar pelos altos preços dos investimentos, evidenciando ainda mais a segregação espacial. A construção de habitações é considerada mercadoria, possuindo valor de uso e valor de troca, estando sujeita aos mecanismos de mercado e depende ainda de outra mercadoria fundamental, a terra urbana.

Tal percepção, não difere muito das demais regiões pesquisadas. A região Norte Fluminense, por exemplo, antes tinha uma economia baseada na atividade agroindustrial, apresentou, durante muito tempo o município de Campos dos Goytacazes, 
como pólo econômico, mas também como principal mercado consumidor da região e concentrador de grande parte da população. Com o desenvolvimento de Macaéê, enquanto sede da Unidade Gestora da Petrobrás da Bacia Petrolífera de Campos, a partir dos anos de 1970, sobretudo, com o rápido crescimento de sua área urbana, a mudança do perfil de ocupação também acontece de maneira muito dinâmica, fazendo com que determinados espaços ganhassem características comerciais e industriais, dando início a um processo de reestruturação sócioespacial. A partir daí, outras empresas, particulares, algumas multinacionais, prestadoras de serviço passam também a montar sedes na cidade ${ }^{22}$.

Piquet (2003) nos chama a atenção de que, se por um lado, questões de ordem natural e logística determinaram a localização da principal base de operações da empresa na região, em Macaé, por outro, em escala regional, Campos dos Goytacazes começa a perder seu posto de núcleo. Com a deterioração da atividade canavieira, a região assistia o despontar de uma nova atividade como um novo pólo gerador de empregos, a indústria extrativa mineral, que tinha como local de sua base de operações a cidade de Macaé. A inserção da indústria petrolífera no cenário regional representa uma nova dinâmica de desenvolvimento, baseada na transição das principais atividades econômicas.

Já o Complexo Logístico Industrial Portuário do Açu, localizado no município de São João da Barra, norte do Estado do Rio de Janeiro, trata-se de um projeto de grande porte caracterizado por uma tipologia portuária diferenciada. Essa tipologia é caracterizada pela necessidade de incorporar grandes áreas retroportuárias o que acaba os distanciando de áreas urbanas consolidadas, assim como, pela facilidade de estar próxima à distritos industriais.

Estudos sobre o tema e sua influência sobre a região e cidades ${ }^{23}$ apontam na direção de um crescimento urbano acelerado, fruto da migração, assim como, para um aumento de problemas urbano-ambientais. Outros estudos ${ }^{24}$ apontam para um crescimento urbano vinculado a um desenvolvimento econômico, com transformações na hierarquia de caráter inicial agrícola para industrial/urbano, com repercussão no desenvolvimento turístico, provocando crescimento nos setores de comercio e serviços, com impacto nas políticas socioambientais.

21 Macaé: Uma análise intra-urbana. Ver em: http://www.abep.nepo.unicamp.br/docs/anais/ outros/5EncNacSobreMigracao/public mac ana urb.pdf. Acesso em 08 de julho de 2015

22 SILVA, Leonardo de Carvalho. Reconfiguração do Norte Fluminense a partir dos anos 70: a chegada do petróleo e suas consequências na dinâmica de crescimento regional. Ver em: http://www.nee.ueg.br/seer/index.php/revistaplurais/ article/viewFile/74/101. Acesso em 09 de julho de 2015. 
[...] alguns municípios da região, principalmente Campos dos Goytacazes e Quissamã, já se preparam para o período pós-petróleo - desenvolvem ousados programas de industrialização com recursos orçamentários próprios - tendo em vista a tendência dos investimentos em capital fixo da economia petrolífera se concentrarem, como já acontece, na faixa litorânea que vai de Macaé a Marica. Já Macaé, dado o poder de polarização do complexo petróleogás, tem dificuldades em implementar ações para um futuro sem petróleo. (CRUZ,2007:45)

Contudo, o cenário promissor, acima descrito, mantendo-se a perspectiva do petróleo permanecer como atividade econômica pujante no território fluminense, passa a exigir um caminho metodológico mediado por condicionantes técnicos, jurídicos e simbólicos. Tal decisão conduz a necessidade de discussão de dois aspectos: por um lado, o papel da legislação urbanística e ambiental, e, por outro viés, a necessária retomada do planejamento, com ótica multidisciplinar e integrada. Ambos os aspectos reforçam a necessidade de se refletir sobre eixos ou temas de desenvolvimento integrado, comprometidos com o uso sustentável do território.

Em alguns municípios pesquisados, sobressaem-se as taxas de crescimento praticadas, com totais superiores a média estadual, da ordem de $1,06 \%$ a. $\mathrm{a}^{25}$.

23 Com destaque os seguintes estudos: Municípios em Dados. Ver em: http://download.rj.gov.br/ documentos/10112/378073/DLFE-23925.pdf/municipios_dados_II.pdf. Acesso em 10 de julho de 2015, o qual tem como objetivo a descrição da dinâmica e o quadro atual dos indicadores municipais apresentados, chamando-se atenção para certas peculiaridades das diferentes regiões; Outro base de informações relevante, trata-se do banco de artigos disponível no Site http://royaltiesdopetroleo.ucam-campos.br - Petróleo, Royalties \& Região - Boletim de Difusão das Informações e Promoção do Debate sobre a Distribuição dos Royalties do Petróleo, com acesso em 14 de janeiro de 2015.

24 Também estudos conduzidos pela Universidade Estadual do Norte Fluminense, no campo das Políticas Sociais, visando contribuir de forma relevante para a mudança do perfil social e econômico da Região. Disponível em: http:// www.uenf.br/portal/index.php/br/, acesso em 20 de abril de 2015. E estudos liderados pela Universidade do Estado do Rio de Janeiro - UERJ, através do seu Instituto de Geografia. Ver em: http://www.e-publicacoes.uerj.br/index.php/ geouerj/article/viewFile/3710/2579. Acesso em 05 de maio de 2015; e pelo Observatório das Metrópoles, Disponível em: http://www.observatoriodasmetropoles.net/download/Os_Estados_e_as_RMs_no_Censo_2010.pdf, sobre Estados e Regiões Metropolitanas constitutivas do Observatório das Metrópoles no Censo 2010. Acesso em 14 de julho de 2015. 


\begin{tabular}{|lccc|}
\multicolumn{1}{r}{ MuUnıcipıo } & LUUU & LU1U & Crescimento 2000- \\
\hline Rio das Ostras & 36.419 & 105.757 & 11,25 \\
Maricá & 76.737 & 127.519 & 5,21 \\
Macaé & 132.461 & 206.748 & 4,55 \\
Cabo Frio & 126.828 & 186.222 & 3,92 \\
Araruama & 82.803 & 112.028 & 3,07 \\
São João da Barra & 27.682 & 32.767 & 1,7 \\
Itaborai & 187.479 & 218.090 & 1,52 \\
Campos dos & 406.989 & 463.545 & 1,31 \\
Goytacazes & 459.451 & 487.327 & 0,59 \\
Niterói & & & \\
\hline
\end{tabular}

Tabela 5.2 - Taxa Geométrica de crescimento dos municípios pesquisados 2000-2010 (arquivo em excel) Fonte: IBGE, Censos Demográficos

Tais resultados, de certa forma, explicam-se pela expansão da metrópole, onde sobressai-se o município de Maricá com 5,21\% a.a, também influenciada pelo anúncio das atividades da indústria petroquímica, e fora da metrópole, influenciado diretamente pelas atividades da industria petrolífera, sobretudo, pela Unidade Gestora da Petrobrás, na Bacia de Campo, o município de Rio das Ostras aparece com $11,25 \%$ a.a. Isto é, impulsionados pelo aquecimento da economia e do mercado de terras desses municípios. Fenômeno este que tem provocado aumento populacional significativo, evidenciando o domínio do urbano sobre o rural.

A partir do quadro acima, podemos observar que o processo de expansão populacional nestas áreas foi intensificando, sobretudo, pela implantação nas regiões Norte, das Baixadas Litorâneas e Metropolitana ( na sua porção leste) de grandes projetos urbanos, o que permitiu articulações entre a metrópole do Rio de Janeiro com estas porções litorâneas do estado. Estas áreas pesquisadas já conviviam com a predominância de atividades de lazer, vinculadas ao turismo e à segunda residência, e atualmente incrementadas também pelos recursos provenientes dos royalties do petróleo.

O tratamento dado às estas cidades passa a ser em função da sua capacidade de atrair grandes investimentos, de assumir uma posição de evidência frente

25 Censos demográficos do IBGE. Taxa de crescimento por regiões: Estado do Rio de Janeiro - 2000/2010. Tabulação Observatório das Metrópoles. Estados e Regiões Metropolitanas constitutivas do Observatório das Metrópoles no Censo 2010. Ver em: http://www.observatoriodasmetropoles.net/download/Os_Estados_e_as_RMs_no_Censo_2010. pdf, Acesso em: 14 de julho de 2015. 
ao quadro político e a mídia e de criar e transformar espaços urbanos, visando, sobretudo, a criação de verdadeiros símbolos para estas cidades. Mas nem sempre é oferecido à região e cidades sob influência dos empreendimentos, alternativas de desenvolvimento urbano, na perspectiva de consagrar a gestão compartilhada do território impactado, através de intervenções estratégicas, estruturantes e com elevado grau de permanência, capazes de influenciar a ocupação e a morfologia urbana, e que ofereçam suporte e condições para o desenvolvimento dos processos de transformação que a região estará submetida, preparando as condições para rearticulação do território e a implementação de um processo de refuncionalização urbana.

Ultrapassar critérios político-administrativos na delimitação de áreas geográficas abre uma perspectiva interessante, pois exige-nos demonstrar as conseqüências da atuação humana sobre o território, a nível local e regional. Ao mesmo tempo que as atividades econômicas, apesar de serem diversas, tendem a guardar uma certa homogeneidade quanto ao nível de desenvolvimento, introduzindo, em diferentes escalas, tensões e conflitos, entre a cidade que pulsa e a urbanização que é delineada, dia a dia, surgem novas formas resultantes de um processo de mudança contínua. Formas estas apoiadas, sobretudo, em dois momentos distintos: o de aceleração virtuosa e o de visibilidade política (ARAUJO,2006:29).

Nesse sentido, não se trata de considerar, o termo "urban sprawl" tal como ele é considerado como um padrão suburbano de urbanização, de espraiamento urbano, por muito autores que tem como base de estudo as aglomerações urbanas norte-americanas ${ }^{26}$, mas sim como uma interpretação deste processo a partir do entendimento do mesmo como fator de dispersão urbana ${ }^{27}$, corroborando para formas urbanas que caminhem no sentido do estabelecimento de inter-relações entre cidades, território e ambiente ${ }^{28}$.

A partir desse entendimento, podemos observar que a relação do território na área de estudo sugere uma forma nova do processo de urbanização o qual se relaciona também com a metropolização do espaço na escala regional. Onde as transformações sócio-urbano-ambientais recentes, por um lado, têm contribuído para evidenciar as consequiências da modernidade, sobretudo, do ponto de vista do surgimento de novas formas espaciais, da apropriação das mesmas e, das tensões entre o ambiente urbano e tecnológico em produção.

${ }^{26}$ Cabe aqui, salientar referências que comungam desta abordagem como KIEFER, M.J. Suburbia and its Discontents. Harvard Design Magazine, n.19, p.1-5., 2003; MEADOWS, D.H. So what can we do - really do - about sprawl. In: Sprawl Articles, Sierra Club, 2009. In: http://www.scielo.br/scielo.php?script=sci_nlinks\&ref=000156\&pid=S01023098200700020000700017\&lng=pt. Acesso em 10 de julho de 2015. 
No entanto, vale a pena ressaltar que nas regiões, objeto da pesquisa, a urbanização dispersa não está necessariamente afeta ao transbordamento da mancha urbana metropolitana. A descontinuidade dessa mancha reporta-se aos efeitos dos empreendimentos, de cunho público ou privado, associados às práticas de reprodução do capital e deslocamentos demográficos consequentes.

(...) essa é uma dimensão que não é associada ao transbordamento puro e simples da mancha urbana da sede metropolitana fagocitando o seu entorno imediato, pois a descontinuidade desta mancha é compensada pela capacidade (ou necessidade) de deslocamento demográfico entre áreas urbanizadas, mas conectadas por fluxos regulares de idas e vindas cotidianas. Essa é uma das características essenciais do processo de dispersão urbana como entendemos aqui, e sugere que o espaço de vida urbano espacialmente desconectado da mancha urbana central é um novo valor agregado aos processos de ocupação urbana mais recente (Ojima, 2007; Hogan \& Ojima, 2008) (...)De acordo com tais estudos, essas espacialidades dispersas são de aglomerações urbanas que apresentam principalmente baixa densidade populacional, urbanização horizontalizada, e uma maior dependência de transporte individual. (OJIMA, 2015:12)

Como modelos de ordenamento na área de estudo, surgem os territórios de fronteira. Como segundo conceito articulador adotado na pesquisa em curso, este é decorrente da apropriação e das representações consequentes, em parte comandados pela especulação imobiliária e desrespeito a áreas protegidas, mas também fruto de um processo de agenciamento ${ }^{29}$. Processo este que extrapola o espaço geográfico, onde tudo pode ser agenciado, ao mesmo tempo territorializado e desterritorializado. Derivado do conceito de território de Deleuze e Guattari, este processo ganha essa amplitude porque ele diz respeito ao pensamento e ao desejo - desejo entendido como uma força criadora e produtiva. (HAESBAERT; BRUCE, 2012).

A partir desse entendimento, observamos nas áreas estudadas que os modelos de ordenamento em curso, são influenciados pelos agenciamentos que ocorrem entre

\footnotetext{
27 Outras referências, como Indovina (1990) e Scott et al. (2001), apontam para a análise de processo semelhante a partir de outras abordagens, como cidade difusa e cidade-região. Ver também OJIMA, R. (2008) Novos Contornos do Crescimento Urbano Brasileiro. O conceito de Urban Sprawl e os desafios para o planejamento regional e ambiental. Em: http://www.uff.br/geographia/ojs/index.php/geographia/article/viewFile/234/221. Acesso em 08 de julho de 2015. 28 Vale citar HORTENCIO, Leonardo M. (2015) Cidade-Região: revisão de conceitos a partir de uma perspectiva histórica, com contribuição que vem buscando através de um olhar baseado no urbanismo, de escala regional, investigar o tema da cidade-região. Ver em: http://xvienanpur.com.br/anais/?wpfb_dl=175. Acesso em 10 de julho de 2015.
} 
os diversos agentes sociais, movidos também pelos interesses, fluxos e intensidades de desejo sobre o território, como meio para a realização das práticas sociais, à luz da dinâmica do capitalismo.

Sobre o último conceito articulador, presente na pesquisa em curso, não podemos deixar de considerar os "empréstimos de território" 30 . Rio das Ostras, por exemplo, empresta território à cidade de Macaé, seja para responder à demanda por moradia, seja para atender à demanda industrial e de serviços especializados. Como é o caso da implantação da Zona Especial de Negócios - ZEN, no limite entre as duas cidades, visando à competição pelo parque empresarial de prestação de serviços à indústria de petróleo e gás. Já a cidade de São João da Barra, pretende se utilizar de grande parte da área urbanizada da cidade de Campos dos Goytacazes. Essa prática exibe contornos de influências causadas por dinâmicas que ultrapassam as fronteiras das cidades, buscando estabelecer um diálogo, nem sempre integrado e articulado, mas de longo alcance que influencia os processos locais e regionais de mudanças, sobretudo, sociais e ecológicas .

Em suma, na perspectiva da escala do território, o que ocorre no espaço da região acaba por determinar a variedade do possível nos espaços singulares, ou seja, o que ocorre no âmbito regional, acaba por influenciar o espaço local.

\subsection{O ESPACO URBANO METROPOLITANO EM UM CONTEXTO DA DISPERSẤO URBANA: REFLEXÕES EM CURSO}

As mudanças estruturais na produção e no emprego, contribuindo para o aumento da mobilidade de empresas e dos negócios, produzem reflexos importantes no espaço metropolitano, uma vez que mudam as relações temporais e espaciais, que, aliadas aos recursos da informática provocam a instantaneidade e a desterritorialização das ações e da informação.

As transformações nas estruturas administrativa e das empresas transnacionais, criam novas necessidades de espaços físicos, de localização geográfica e de

29 Ver em HAESBAERT, Rogério\& BRUCE, Glauco. A Desterritorialização na obra de Deleuze e Guattari. Ver em: http://www.uff.br/geographia/ojs/index.php/geographia/article/viewFile/74/72. Acesso em 12 de julho de 2015.

30 "Empréstimo de Território" - Conceito introduzido pela autora em sua Tese de Doutoramento em Urbanismo. Trata-se de prática de empréstimo de territórios entre cidades, que estabelece lógicas de relações, interfuncionalidades e contigüidades, seja para responder à demanda por moradia, seja para atender à demanda industrial e de serviços especializados. Ver ARAUJO, E.C. Paisagem da Utopia: novas formas espaciais instituintes no ambiente urbano e tecnológico da Bacia de Campos. Tese de Doutorado em Urbanismo. UFRJ/FAU/PROURB, 2006. 
interconexões operacionais. Esta nova organização acaba por revelar duas forças opostas na estrutura espacial da região: a dispersão e a centralização, sendo que a primeira, tendo o seu potencial de dispersão geográfica potencializado pela telemática, modifica o modelo tradicional de expansão e urbanização e a própria inter-relação do núcleo central da Região Metropolitana com as demais cidades.

A cidade está mudando e ganhando o sentido de região, necessitando se articular com o entorno metropolitano, sua área de influência. Esta mudança pressupõe o surgimento de uma economia urbana ou regional articulada à novas escalas. Onde se verificam exigências de diálogo entre a ordem ambiental e a ordem urbana, realinhamento de demandas - do passado, do presente e do futuro, com a prospecção de cenários futuros. Ao lidar com a escala regional, a cidade metropolitana vivencia a experiência de planejar e governar uma cidade multimunicipal.

$\mathrm{Na}$ realidade, duas concepções de ordenamento evidenciam o confronto - o municipal e o regional - refletindo sobre o seu potencial de convergência prática. Por um lado, intensifica-se a ocupação das centralidades existentes, por outro, alargamse, em perímetro e intensidade, as urbanizações ilegais.

Mas presenciamos também a intensificação da segunda residência, assim como, assentamentos urbanos em áreas recentemente transformadas do rural para o urbano, isoladas no campo, com tipologias unifamiliares. Por outro, nos deparamos também com ambiências urbanas densas e de tipologias plurifamiliares, com infraestruturas incipientes, equipamentos básicos escassos e espaço urbano pouco qualificado. Em grande parte, estes assentamentos, voltados para a classe média baixa, média, média alta e alta, ainda são muito dependentes das centralidades já existentes, acentuando o uso do automóvel e revelando as péssimas condições de mobilidade da metrópole. $\mathrm{O}$ que se verifica, de forma crescente, movido na esteira da influência dos grandes projetos urbanos, é um mercado de terras que se amplia e potencializa alterações significativas no uso do solo, replicando, multiplicando e afastando as frentes de urbanização, como práticas que se operacionalizam a partir dos interesses do capital.

A região metropolitana do Rio de Janeiro, embora carecendo ainda de um aparato institucional/legal que dê conta das suas demandas em escala regional ${ }^{13}$, convive, em grande parte, com práticas decorrentes de decisões avulsas e casuísticas. Este modo de aprovação das urbanizações da iniciativa dos particulares, no âmbito local, com efeitos sobre territórios de fronteira metropolitana, favorece a dispersão das áreas urbanas, ainda muito dependentes da oferta de transporte coletivo, dada a deficiente infraestrutura da rede viária e de transporte público de massa.

$\mathrm{Na}$ esteira do conceito de grande projeto urbano, introduzido por Moura (2011), projetos industriais associados ao território em análise podem ser considerados como objetos insubordinados. Fruto de intencionalidades mercantis e simbólicas que transcendem o lugar, e que são indiferentes a ele $^{32}$. 
Deste modo, Maricá e Itaboraí, influenciados e impactados pelo Complexo Petroquímico do Rio de Janeiro - COMPERJ, se destacam não somente pelo ritmo do seu crescimento populacional, mas também pela dinâmica acelerada de transformação do espaço-tempo, definindo uma forma metropolitana singular onde a cidade metropolitana surge com um protagonismo frente à região.

Nos planos territoriais pesquisados, considerando os Planos Diretores Municipais e Plano Diretor de Estruturação Territorial do Leste Fluminense (PETLeste $^{33}$, proposto para a região, pode-se identificar um conjunto de tendências comuns, a partir da visão de um território comprometido com a implantação e com os impactos gerados pelo Complexo Petroquímico do Rio de Janeiro - COMPERJ e pelo Arco Metropolitano ${ }^{34}$ : áreas urbanizáveis de grandes dimensões, suportadas em perspectivas de crescimento já não anteriormente imagináveis; pouca atenção dada à cidade existente; pouco interesse sobre redutos de espaço rural; dificuldade em interpretar e ordenar as dinâmicas que afetam as franjas urbanas; admissibilidade de construção nas proximidades à áreas verdes (áreas florestais, agroflorestais, áreas de preservação permanente, unidades de conservação), de vários usos (habitação, indústria, equipamentos, turismo, entre outros); demanda por implantação de redes de infraestruturas e de equipamentos; dentre outros aspectos. Como promover a convergência dos dois modelos? Um de escala local e outro na escala regional. No plano local, verifica-se a preocupação com três frentes de atuação. A de estabilizar a mancha urbana, a de (re) estruturar a cidade dispersa e, por fim, a de revalorizar a cidade existente. Mas preocupa-nos a falta de transições entre as diferentes regiões e sub-regiões. Elementos de transição entre sistemas gerais, como por exemplo, as grandes vias e os sistemas locais que poderiam dialogar com os territórios de fronteira.

Atualmente nos deparamos, de forma cada vez mais dominante, com territórios que se apresentam com sistema de urbanização alargada ou difusa. As áreas centrais tradicionais deixaram de ser únicas, para serem cada vez mais complementares de outras áreas centrais. Deparamo-nos, na contemporaneidade, com uma cidade-território, com estratégias ora

\footnotetext{
${ }^{31}$ Só muito recentemente foi criado pelo Governo do Estado do Rio de Janeiro, Câmara Metropolitana de Integração Governamental, através do DECRETO No 44.905 DE 11 DE AGOSTO DE 2014. Iniciativa visa promover a integração de políticas urbanas desenvolvidas pelo Estado e pelos Municípios da Região Metropolitana. 32 Conceito presente in: Moura, R., 2011, com base em Santos,M, 1996.

33 O plano tem o objetivo de apoiar o Conleste (Consórcio Intermunicipal de Desenvolvimento do Leste Fluminense) e fornecer subsídios de planejamento para a Câmara Metropolitana de Integração Governamental do Rio de Janeiro (CIG).
} 
consensuadas a partir dos serviços de interesse metropolitano ou tendemos a uma estratégia de competição, ditada pelo mercado ou pelo oportunismo político - e aí será certamente uma competição desigual. [...] As questões novas estão circunstanciadas a uma cidade-território ou a uma metrópole expandida que estrutura continuidade, mudanças de ambiente e ritmo. (ARAUJO; RUFINO, 2014:12)

\subsection{TRAJETÓRIA DE PESQUISA AINDA A SER PERCORRIDA}

A partir desse entendimento, procurou-se, no presente artigo, salientar a importância em adotar uma visão multidimensional, complexa e dinâmica de abordagem escolhida no que diz respeito aos processos de urbanização e ambiente no contexto de parte do território fluminense, com múltiplas interpretações quanto ao fenômeno da dispersão urbana.

Podemos destacar a partir do que aqui foi apresentado, alguns aspectos a serem valorizados no planejamento territorial como, por exemplo: a necessidade de criação e/ou adequação de alternativas de sistema de transportes no âmbito do deslocamento de pessoas e cargas; a necessidade de indicação de áreas adequadas à implantação de bairros planejados para assentamento de população e infraestrutura social; a necessidade de levar em consideração o contexto ambiental urbano também na escala regional.

O quadro descrito nas seções anteriores nos possibilita perceber que o processo socioeconômico rápido e intenso, vivenciado pelas cidades que são influenciadas e impactadas por grandes projetos urbanos provoca grandes distorções e conflitos no território. O que necessita de um planejamento territorial capaz de responder as novas demandas resultantes desse crescimento econômico e populacional, apontando um grande desafio para o desenvolvimento sustentável do território.

Os projetos previstos na região já são suficientes para produzir significativos impactos, pela sua difusão no espaço regional, pelo porte e pela natureza estratégica dos mesmos. Mesmo que postos de trabalho sejam criados e posteriormente desacelerados, movimento de transformação da estrutura fundiária seja formalizado, estruturas de uso do solo sejam adequadas para acolhimento das transformações

\footnotetext{
33 O plano tem o objetivo de apoiar o Conleste (Consórcio Intermunicipal de Desenvolvimento do Leste Fluminense) e fornecer subsídios de planejamento para a Câmara Metropolitana de Integração Governamental do Rio de Janeiro (CIG).

34 Rodovia, em construção, ao funda da Baía de Guanabara, no entorno da Região Metropolitana do Rio de Janeiro, com a finalidade de integrar o Porto de Itaguaí ao COMPERJ, no município de Itaboraí.
} 
urbano-ambientais em curso, os impactos são inegáveis.

Resultados iniciais sobre a paisagem urbana de cidades como São João da Barra, Campos e Macaé, na região Norte, Rio das Ostras, Cabo Frio e Araruama, na região das Baixadas Litorâneas e Niterói, Maricá e Itaboraí, na região Metropolitana, levam a investigação a considerar que o recente processo de urbanização, passa pela necessidade de ordenação da paisagem urbana.

A cidade de Niterói, como núcleo da região leste metropolitana, com investigação em curso sobre iniciativas de recuperação da qualidade espacial de ambientes urbanos, vem sendo objeto de pesquisa no âmbito dos instrumentos jurídico-urbanísticos e também no que tange às características morfológicas do espaço urbano e seus impactos sobre o ambiente. Já o município de Araruama, litoral fluminense, tem sua pesquisa orientada para o campo da infraestrutura urbana, e, como esta vem direcionando o processo de urbanização.

É evidente que a diversidade dos aspectos abarcados pela herança de problemas e pelas intervenções, já em curso, aponta para a necessidade de um planejamento urbano e regional, que dê conta de seu caráter multiescalar, interinstitucional, multidimensional, com visão estratégica e inter setorial, (ALBUQUERQUE, 1997).

Ao incorporar a escala regional ao planejamento das cidades, os planos diretores, prescindem de observar tanto a definição de áreas urbanas e naturais quanto o adensamento sustentável para se evitar o alastramento da mancha urbana sobre áreas naturais, de preservação e cultiváveis.

A velocidade imposta pela dinâmica urbana, observada nas cidades objeto da presente pesquisa, provoca o surgimento de novas formas. A análise aqui apresentada, face às múltiplas disfunções no território estudado, marcadas por um urbanismo expansivo e desorganizado e problemas ambientais graves, com pressão sobre ecossistemas frágeis (orla costeira, restingas, rede hidrográfica, sistema lagunar), e ainda a expectativa, seja dos impactos, seja das influências dos empreendimentos em curso, aponta para a deflagração de um sem número de transformações. Entre estas, destaca-se o aumento populacional, migratório, atraído não só pelas oportunidades industriais, mas também na melhoria das estruturas dos serviços públicos. Nesse sentido, é necessário avaliar os impactos gerados pela implantação de grandes projetos, visando, sobretudo, contribuir para que projetos decorrentes alcancem a promoção do desenvolvimento da região em que forem instalados.

Como se pode constatar ao longo deste artigo, o diagnóstico dos problemas sobre os territórios estudados, a partir de uma revisão conceitual, aponta para insuficiências estruturais decorrentes, em grande parte do processo de dispersão urbana e suas múltiplas facetas. 
(...) A pressão urbana exercida por Macaé vai deslocando o fenômeno urbano para ambientes de fronteira, como é o caso de Rio das Ostras. Essa pode ser explicada através do conceito de escala, ou melhor de territorialidade, considerando atributos físico-geográfico e imaterial; do conceito de temporalidade, resultante das dinâmicas políticas sobre o urbano, das atividades no espaço; e do conceito de qualidade (ambiental-urbana), associado além da matriz de ordenação da paisagem (paisagem como valor ambiental) à vitalidade urbana (ARAUJO, 2006:233).

A questão posta refere-se à ausência de mecanismos/instrumentos eficazes para se enfrentar resistências e se levar à prática estratégias e políticas setoriais. Tais práticas, em um contexto de dispersão urbana, apresentam contorno supramunicipal, sem, no entanto, ser retirada a autonomia no licenciamento da urbanização, no campo municipal. Só quando esta visão for superada, será possível passar dos planos à sua concretização, criando desse modo às condições para que o processo de transformação em curso, nos territórios pesquisados, seja efetivamente conduzido pelos poderes públicos segundo objetivos de interesse coletivo, com preocupação com mudanças ambientais e transformações sociais.

\section{REFERÊNCIAS}

ALBUQUERQUE, Francisco. Metodologia para el desarrollo economico local. Instituto

Americano y del Caribe de Planificación Econommica y social. Santiago, Chile: ILPES/ CEPAL, 1997.

ARAUJO, E. C. de. "Urban Planning as an Instrument of Local Governance Arrangements: committed to regional sustainability". 4th URBENVIRON International Seminar on Environmental Planning and Management. UFF, Niterói, 2010.

ARAUJO, E. C. Paisagem da Utopia: novas formas espaciais instituintes no ambiente urbano e tecnológico da Bacia de Campos. Tese de Doutorado em Urbanismo. UFRJ/FAU/PROURB, 2006.

ARAUJO, E. C. Problemas urbano-ambientais e o direito à cidade. Anais do XIII Simpósio de Geografia Urbana. UERJ, 2013.

ARAUJO, E.C. \& RUFINO, W. Direitos Sociais e Políticas Públicas: diálogo conflituoso nas regiões metropolitanas brasileiras. CONPEDI, 2014.

BOLETIM Petróleo, Royalties e Região. Campos dos Goytacazes: CEPECAM/ UCAM Campos, diversos.

CARLOS, Ana Fani A. VOlOCHKO, Danilo, AlVAREZ, Isabel Pinto. (Orgs.) A 
Cidade como negócio. São Paulo: Editora Contexto, 2015

CEPERJ. Fundação Centro Estadual de Estatística, Pesquisas e Formação de Servidores Públicos do Estado do Rio de Janeiro. Ver em: http://www.ceperj. rj.gov.br/ceep/info_territorios/divis_politico_administrativo.html. Acesso em 18 de julho de 2015.

CRUZ, José Luiz Vianna. Os desafios do Norte e do Noroeste Fluminenses frente aos grandes projetos estratégicos. CEFET. Campos dos Goytacazes - RJ.VÉRTICES, v. 9, n. 1/3, jan./dez. 2007. Ver em: file://C:/Users/hp/Downloads/50-177-1-PB. pdf. Acesso em 07 de julho de 2015.

GUIDDENS, Anthony. As Conseqüências da Modernidade. São Paulo: UNESP, 1991.

HAESBAERT, Rogério\& BRUCE, Glauco. A Desterritorialização na obra de Deleuze e Guattari. Ver em: http://www.uff.br/geographia/ojs/index.php/geographia/ article/viewFile/74/72. Acesso em 12 de julho de 2015.

HARVEY, David. Condição pós-moderna. C: Loyola, 2005.

HOLZER, Werther; CRICHYNO, Jorge; BAHIENSE, Marcos de Castro M.; REYNALDO, Flávia M. S.; Urbanização Dispersa: estudo de caso em Maricá. - Rio de Janeiro: Garamond, 2009.

http://www.e-publicacoes.uerj.br/index.php/geouerj/article/viewFile/3710/2579. Acesso em 10 de julho de 2015.

IBGE. Contagem de População de 1996 e Censo de 2010. Disponível em: http:// cidades.ibge.gov.br/xtras/perfil.php, acesso em 20 de abril de 2015.

INDOVINA, F. La cittá diffusa. Venezia: Daest (Dipartimento di Analisi Economica e Sociale del Território) Ed., 1990.

LEFEBVRE, Henri. Lógica formal, lógica dialética. Rio de Janeiro: Civilização Brasileira, 1995

LEFEBVRE, Henri. O Direito à Cidade. São Paulo: Ed. Moraes, 1991.

MACAÉ: UMA ANÁLISE INTRA-URBANA. Ver em: http://www.abep.nepo. unicamp.br/docs/anais/outros/5EncNacSobreMigracao/public_mac_ana_urb. pdf. Acesso em 08 de julho de 2015

MARANDOLA, E., Jr.. Cidades médias em contexto metropolitano: hierarquias e mobilidades nas formas urbanas. In R. Baeninger (Org.), População e cidades: subsídios para o planejamento e para as políticas sociais (p.187-207). Campinas: NEPO/Unicamp; Brasília: UNFPA, 2010.

MOURA, R. Arranjos Urbano-regionais no Brasil - o conteúdo modificado da concentração e da desigualdade. Revista Paranaense de Desenvolvimento, 115, 199-210, 2010.

MOURA, R. Grandes projetos urbanos e planejamento territorial. Boletim Campineiro de Geografia. V1. no. 1, 2011. 
OJIMA, R. Novos contornos do crescimento urbano brasileiro? O conceito de urban sprawl e os desafios para o planejamento regional e ambiental. GEOgraphia, 10(19), 46-59, 2008

OJIMA, R., Monteiro, F. F., \& Nascimento, T. C. L. Urbanização dispersa e mobilidade no contexto metropolitano de Natal: a dinâmica da população e a ampliação do espaço de vida. URBE. Revista Brasileira de Gestão Urbana (Brazilian Journal of Urban Management), 2015 jan./abr., 7(1), 9-20. Ver em : http://www.scielo.br/pdf/urbe/v7n1/2175-3369-urbe-7-1-0009.pdf. Acesso em 05 de julho de 2015.

OJIMA, Ricardo. Dimensões da urbanização dispersa e proposta metodológica para estudos comparativos: uma abordagem socioespacial em aglomerações urbanas brasileiras. Revista Brasileira de Estudos Populacionais, São Paulo, v. 24, n. 2, p. 277- 300, jul./dez. 2007.

OLIVEIRA, F. J. G. de. Reestruturação produtiva: território e poder no Estado do Rio de Janeiro: Garamond, 2008.

PINTO, Roberta Mariana Ferreira Mori; CASSEMIRO, Rafael Fernandes; VAZ, Alexssandra Juliane; CARDOSO, Suellem Priscila de Carvalho. Região da Baixada Litorânea do Rio de Janeiro: interações entre o turismo e urbanização. Espaço \& Geografia, Vol.14, No. 2, 191:223, 2011. Ver em: file://C:/Users/hp/ Downloads/142-414-1-PB.pdf. Acesso em 08 de julho de 2015.

PIQUET, Rosélia. Novo Recorte Regional do Norte Fluminense. Trabalho Apresentado na ANPUR de 2003.

PIQUET, Rosélia. O norte fluminense em tempo presente. In: Rio de Janeiro: um olhar socioespacial. PENALVA et alii (orgs.). Rio de Janeiro: Gramma, 2010.

RANGEL, Larissa C.; PESSANHA, Leonardo Ribeiro M. O Complexo Logístico Industrial Portuário do Açu e os seus Impactos no Sistema de Drenagem e na Estruturação Urbana da Região Norte Fluminense. Revista RBEUR, no.930. Ver em: http://unuhospedagem.com.br/revista/rbeur/index.php/anais/article/ viewFile/4366/4235. Acesso em 09 de julho de 2015.

REIS, Nestor Goulart (org.). Sobre Dispersão Urbana, São Paulo, Via das Artes, 2009 REIS, Nestor Goulart. Sobre a dispersão em São Paulo. In: PORTAS, Nuno; TANAKA, Marta. (coord.). Dispersão Urbana - diálogos sobre pesquisas no Brasil - Europa, São Paulo, FAUUSP, p.49-58, 2007

RIBEIRO, Miguel A.\&O’NEILL, Maria Monica C. Contrastes entre a Metrópole e o Interior Fluminense a partir da dinâmica populacional. Geo UERJ - Ano 14, $n^{\circ} .23$, v. 1, 2012, p. 262-301. Ver em:

ROCHA, Rita; BIENENSTEIN, Regina; SIQUEIRA, Washington Luiz Cardoso. Mobilidade Urbana e Dominância Viária em Cidades Médias: influências do COMPERJ e AMRJ em Maricá, RJ, Brasil. 
Ver em: http://observatoriogeograficoamericalatina.org.mx/egal13/ Geografiasocioeconomica/Geografiaurbana/018.pdf. Acesso em 03 de julho de 2015.

SANTOS, Milton. O retorno ao território. IN: SANTOS, M. et al. (orgs.) Território, Globalização e Fragmentação. São Paulo: Hucitec, p. 15-20, 1996.

SANTOS, Milton. O retorno do território. In: SANTOS et al (orgs.) Território: globalização e fragmentação, São Paulo, HUCITEC, ANPUR, 1994

SCOTT, A. J.; AGNEW, J.; SOJA, E. W.; STORPER, M. Cidades-regiões globais. Espaço e Debates, São Paulo, n.41, p.11-25, 2001.

SILVA, Leonardo de Carvalho. Reconfiguração do Norte Fluminense a partir dos anos 70: a chegada do petróleo e suas consequências na dinâmica de crescimento regional. Ver em: http://www.nee.ueg.br/seer/index.php/revistaplurais/article/ viewFile/74/101. Acesso em 09 de julho de 2015.

TOFFANO, Ana Luiza. VALOTO, Fernanda M. Grandes Projetos Urbanos no Estado do Rio de Janeiro: a influência da insdustria do petróleo na Região da Ompetro e do Conleste. Cadernos de Pós-graduação em Arquitetura e Urbanismo - 2011 Ver in: http://www.mackenzie.br/dhtm/seer/index.php/cpgau/article/viewFile/ Toffano.2011.1/532, Visitado em 03 de novembro de 2014. 
